\title{
ANALYTIC HIERARCHY PROCESS FOR RURAL MICRO PROJECT SUSTAINABILITY MONITORING IN NEPAL
}

\author{
Shashi Bhattarai* \\ Development Dynamics Pvt. Ltd. \\ GPO Box 2897, Kathmandu, Nepal \\ E-mail: shashi@icon.com.np \\ Barun Kanta Adhikari \\ WaterAid Nepal, Kupundol, Lalitpur Nepal \\ E-mail: barunkantaadhikari@wateraidnepal.org.np
}

\begin{abstract}
This paper intends to disseminate knowledge and experience gained on designing and implementing a multi criteria analysis based framework for sustainability monitoring of community managed projects in rural Nepal. The multi criteria analysis based sustainability monitoring framework is designed to be used at different levels. At the ground level, the implementing agency is a local non-governmental organization (NGO) and in this case at the top level, the funding agency is an international nongovernmental organization (INGO) - WaterAid Nepal. The bottom level framework is based on a weighted spreadsheet for participatory information collection, and at the top level, the same information is used in an analytic hierarchy process (AHP) framework to make decisions for resource allocation for sustainability enhancement.

In this paper, we have discussed the initial development and pilot testing performed in 2007, and subsequent improvement and use of the multi criteria analysis based sustainability monitoring framework by various partners of WaterAid Nepal. The objective of developing the framework is to monitor the sustainability status of each project through multiple criteria, consisting of various indicators on technical, socio-environmental, financial and institutional aspects. Integrated assessments of four criteria, including various factors and sub-factors within each criterion, were conducted to evaluate the status of sustainability in an integrated / holistic manner with the beneficiaries' participation. In the paper, we have also cited the earlier dissemination of the work in international forums held in Bangladesh and Pakistan.
\end{abstract}

Keywords: AHP, Sustainability monitoring, Nepal, Water Supply, Sanitation

\section{Introduction}

"Sustainability" is a well-liked term in modern development practices and discourses, and is understood in many ways according to the situation in which it is applied. It has become a complex term that can be applied to almost every system on earth. In fact, the earth's resources are limited and all human activity should emphasize the sustainable use of it. According to IUCN, UNEP and WWF (IUCN et al., 1991), sustainability consists of "improving the quality of human life while living within the carrying capacity of supporting eco-systems". When we talk about the sustainability of any infrastructure for instance, it is a necessary requirement for achieving the sustainability of other human undertakings as well. As an example, sustainability of fishing business is dependent on the sustainability of a clean water body. Sustainability is also directly associated with the value for money of the investment made in the development sectors. The Alliance for Global Sustainability Research Report states that "some developing countries become trapped in a civil infrastructure cost spiral, where they set aside the increasing amount of resources for building the infrastructure and devote less

\footnotetext{
${ }^{*}$ Corresponding author
} 
and less to maintenance and repair" (Takashi, 2004). Often, there is no systematic expenditure for rehabilitation and improvement. Because re-building the infrastructure has a much larger consequence both on the economy and also on the environment, the development of a maintenance system consisting of reliable and economical monitoring methods and design/maintenance strategies to minimize life-cycle cost is crucial for sustainable development.

The issue of sustainability could therefore pertain more to poor countries including Nepal, where most infrastructure is constructed through one-time donors' support or government investments. The infrastructure, after it is constructed and handed over to the concerned authority is either never looked after or poorly managed by the concern authority until it reaches a totally defunct stage. Based on objectives set by the stakeholders of the project, there may be different views the sustainability aspect of the project. Poverty assessment research has consistently showed that improvement in water services is a core element in most strategies designed to alleviate poverty. In this study, sustainability of the drinking water, sanitation, hygiene projects is viewed as an amalgam of technical, social/environmental, financial, and institutional dimensions.

\subsection{Measuring sustainability}

Measuring the sustainability status of any infrastructure is a complex job and offers many opportunities for argument. Development workers and evaluators have a tough time while making complex decisions around prioritizing old projects in terms of sustainability status, proportionate investment for rehabilitation, making public service policies, etc. There are no perfect indicators to measure sustainability, but there are agencies which provide indicators that address the critical issues of sustainability (eg. Sustainable Measures, 2009). The fundamental integrated dimensions of sustainability are often taken to be: ecological, social and economic, also known as the "three pillars" that govern the sustainability (Adams, 2006). These three elements are also referred as Pillars, Circles or Interlocking Circles to show visual representations of sustainable development by the author. Longer term sustainability is certainly a desired end result expected from most of the human undertakings in the infrastructure sector, which is governed by a number of sustainability dimensions, corresponding factors and sometimes many sub-factors in a complex manner. This sustainability monitoring exercise adopted the project implementer's (WaterAid Nepal) agreed preset standards, definitions, indicators, before venturing into the monitoring process.

As setting indicators for sustainability monitoring is a complex job, selecting the most reliable and pragmatic analysis tool for fact-finding is also an equally complex undertaking in the development sector. Multi Criteria Analysis (MCA) is a process of integrated assessment of a finite set of projects, in a structured way to determine overall preference among alternatives, where the alternatives accomplish several objectives. The advantage of the MCA processes is that it enables an integrated assessment of subjective and objective information with stakeholders' values in a single framework. Different MCA methods have been widely used in the area of environmental resources planning and management (Panthi and Bhattarai, 2008).

While various MCA tools are available, the appropriate integrated decision-modeling tool for developing countries, singly or in combination with other MCA or non-MCA tools, is still the subject of research. However, the simplest form of MCA, called the Weighted Table (WT) method, is found appropriate for micro projects to use at local level at the initial stage. AHP based MCA is appropriate for higher level use for resource allocation to micro projects like rural water supply (Bhattarai and Adhikari, 2008).

\subsection{Sustainability of community managed water, sanitation and hygiene projects in Nepal}

On paper Nepal appears on track to meet both the water and sanitation Millennium Development Goals (MDGs of the United Nations). As per the sector ministry's estimates in 2008, drinking water service coverage stands at $81 \%$ and sanitation coverage at $46 \%$. But it is commonly accepted that these figures do not reflect the challenging realities for the sector on the ground. According to a survey, out of the 5,000 water points observed in 22 hill districts, only 21 percent were found to be 
functioning as designed, 56 percent required major repair, and 21 percent needed complete rehabilitation (DWSS and WAN, 2003). The Looking Back Study conducted by WaterAid Nepal and Nepal Water for Health (NEWAH, 2005) concluded that out of 6,278 water points visited, $30 \%$ were found to be functioning to design, $50 \%$ required attention and $20 \%$ were not functioning. These facts highlight the extent of the sustainability problems for water supply services in Nepal and warrant serious enquiry at concerned authority levels. If we look at the water-sanitation sector, there are no policies or mechanisms to monitor old projects in many implementing agencies. Despite ample examples of sustainability assessments carried out by few sector players for their own purposes, there are no centrally set definitions, norms and standards of the government that have to be followed by other sector players.

\subsection{Need for a sustainability monitoring mechanism in Nepal}

Nepal started a systematic development planning process around 1960. By then, drinking water had been one of the continued development agendas of the nation, and many projects were executed in the past by government and other agencies throughout the country. The sustainability of community managed water supply projects is a major concern in developing countries including Nepal, to justify the investments made in the sector. At the moment, in fact, there is no authoritative answer to questions such as - how many projects were implemented in the past in Nepal with respect to any base year; where were they implemented; who implemented them; who was benefited; how much was invested; and more importantly what is the current functioning status of those projects. There is a need to break with this legacy and develop some mechanisms so that the comparative status of completed projects can be realized at any time.

\section{Application of MCA for long term sustainability monitoring}

WaterAid Nepal, an international non-governmental organization working in Nepal for the last 20 years, is not spotless with regards to the above shortcomings. WaterAid Nepal is striving to develop and establish some mechanisms for its own purposes and to the benefit of all involved in promoting water and sanitation services in Nepal and elsewhere. At the organizational level, there was an immense need for a pragmatic, productive and regular sustainability monitoring system to be put in place at WaterAid Nepal and its implementing partner level to demonstrate the 'value for money' for donor's support. With the experience from the Looking Back study conducted by WAN through NEWAH (NEWAH, 2005), WaterAid Nepal and a consulting firm, Integrated Consultants Nepal (ICON), conceptualized the long term sustainability monitoring mechanism in 2006 using Multi Criteria Approaches (WAN, 2007).

\subsection{MCA model used for long term sustainability monitoring (witness WaterAid Nepal)}

\subsubsection{Water, sanitation and hygiene as separate goals}

WAN has supported a range of projects in the past; they include stand alone projects or different combinations of water, sanitation and hygiene components in a single project. The water, sanitation and hygiene (WASH) related activities are usually implemented together in a project; however their technical and management aspects are quite different. Therefore, each component was dealt separately while assessing the sustainability of the services; even though they contribute better impacts in people's health and livelihoods when used collectively.

\subsubsection{Key sustainability dimensions}

Dimensions are the highest level of sustainability monitoring indicators. For water supply and sanitation facilities, four monitoring dimensions are used: technical, socio-environmental, financial and institutional. In the case of hygiene; water facility, sanitation facility, hygiene behavior and institutional are taken as the key dimensions. 
$\underline{\text { For water and sanitation }}$

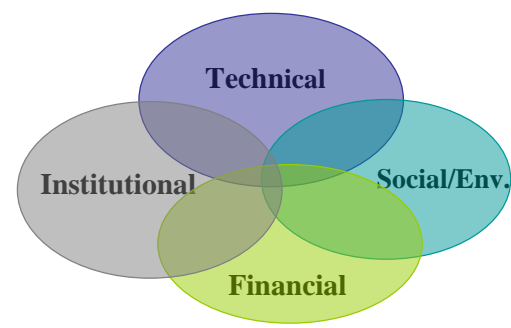

For hygiene

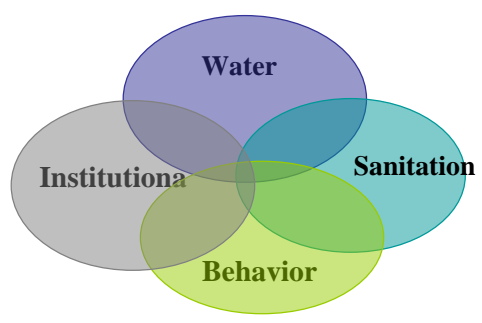

Figure 1. Sustainability dimensions for water, sanitation and hygiene services

\subsubsection{Factors and sub-factors contributing to key dimensions}

Each sustainability dimension is significantly governed by many factors and sub-factors. For example, 'technical' as one of the sustainability dimensions of water supply services is greatly governed by four key factors: source yield and water quality, physical condition of engineering components, functioning of water point and meeting required demand. The factor "functioning of water point" is further divided into three sub-factors: maintaining design flow, water quality at tap and surrounding condition.

\subsubsection{Core factors among sustainability factors}

Core factors are considered the most important sustainability factors. Each core factor is considered as 'core' to making its corresponding service sector sustained or not sustained. WaterAid Nepal has identified 2 core factors each for water and sanitation services and one core factor for the hygiene sector. Please refer to Table-1 below for selected core factors.

Table1. Core sustainability factors

\begin{tabular}{|l|l|}
\hline Sectors & Core sustainability factors \\
\hline \multirow{2}{*}{ Water } & 1. Design flow is maintained at all water points throughout the year \\
\cline { 2 - 2 } & 2. Targeted population is benefited by all water points of the project \\
\hline \multirow{2}{*}{ Sanitation } & 1. All family members are using hygienic latrines \\
\cline { 2 - 2 } & $\begin{array}{l}\text { 2. No open defecation (NOD) status declared in the community } \\
\text { Hygiene } \\
\text { eating using safe cleansing materials. }\end{array}$ \\
\hline
\end{tabular}

\subsubsection{Grading of dimensions, factors and sub factors}

As per the principles of multi criteria approaches, each set criteria is rated depending upon its potential contribution or its significance in making the case sustainable. The comparative weights given to dimensions, factors and sub factors were determined through participatory methods involving sector professionals and field workers. Further, each factor and sub-factors is rated considering its significance to make the case sustainable. Please refer to Figure-2 for the rates (importance) given to each and every dimension and factor of water sustainability as an example. 


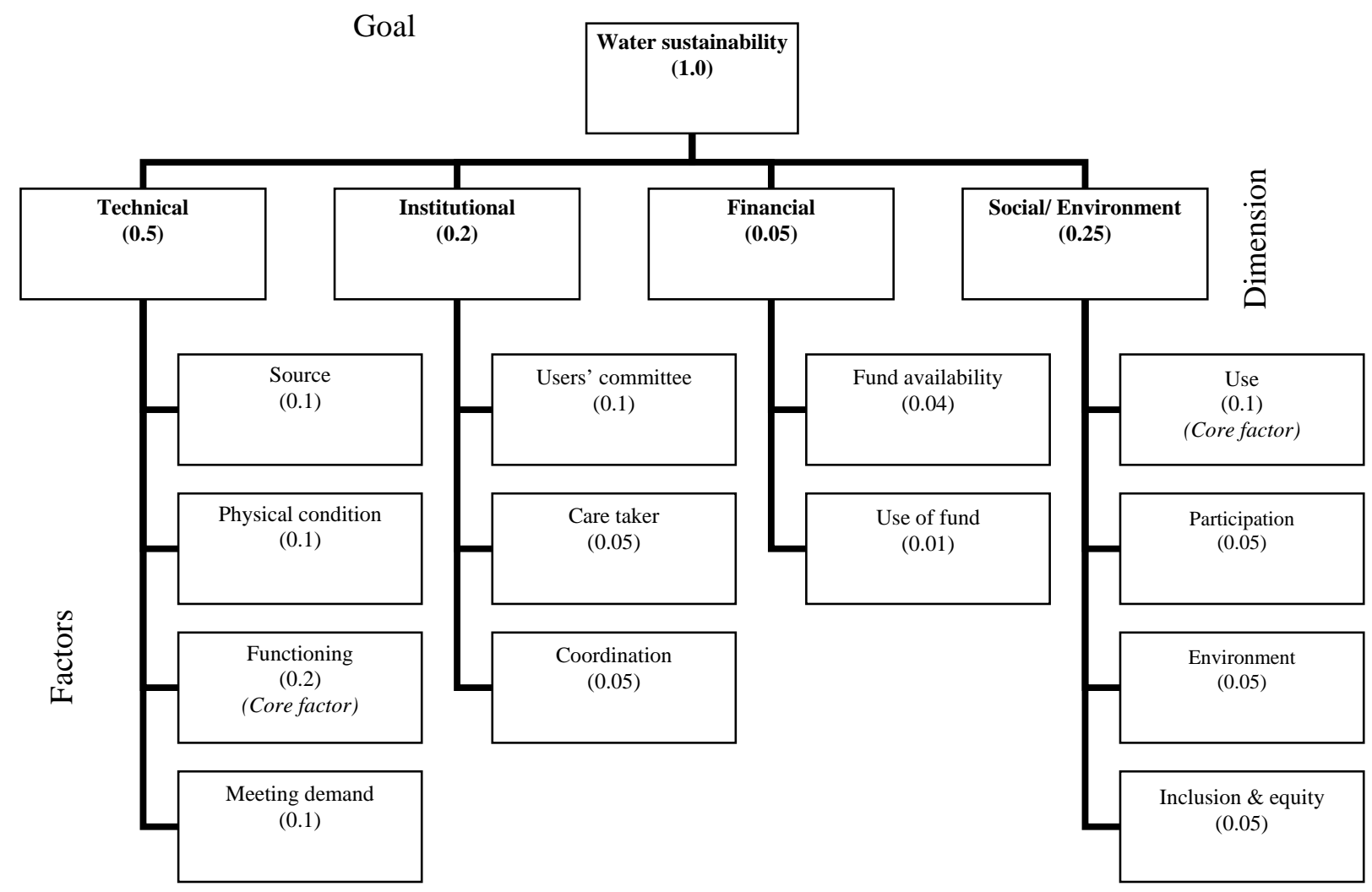

Figure 2. Hierarchical structure of goal, dimensions and factors with their weights adopted for drinking water facilities.

\subsubsection{Focus on sub-factors}

Sub-factors are the lowest level contributors, therefore, classification, measurement and ranking system is done manually at this level only. Depending upon the required attributions of the particular sub factor, it is measured through a measurement system of grade points $(5,4,3)$ as shown in Table 2 below. The enumerator classifies each and every sub-factor in terms of excellent (E), very good (VG), good $(\mathrm{G})$, fair (F) and poor (P) in the field using different tools, guidelines and judgments.

Table 2. Classification, measurement and ranking of sub-factors

\begin{tabular}{|l|l|l|l|l|}
\hline \multirow{2}{*}{$\begin{array}{l}\text { Classification } \\
\text { of sub-factor }\end{array}$} & \multicolumn{2}{|l|}{ Range for measurement } & \multirow{2}{*}{$\begin{array}{l}\text { Sustainability } \\
\text { ranking of sub-factor }\end{array}$} \\
\cline { 2 - 3 } & Five points & Four points & Three points & \\
\hline Excellent & $80-100 \%$ & $70-100 \%$ & $70-100 \%$ & Sustained (s) \\
\hline Very good & $70-79 \%$ & $70-79 \%$ & & \\
\hline Good & $50-69 \%$ & $50-69 \%$ & \multirow{2}{*}{$30-69 \%$} & \multirow{2}{*}{ Not sustained (ns) } \\
\hline Fair & $30-49 \%$ & $30-49 \%$ & & \\
\hline Poor & $<30 \%$ & $<30 \%$ & $<30 \%$ & \\
\hline
\end{tabular}

\subsection{Sustainability ranking process}

Projects are ranked in terms of sustained, sustained but at risk and not sustained projects. The objective of this type of ranking was to help decisions for future investment. The assumption is that WaterAid does not need to provide any support for sustained projects, needs to provide some follow up support to sustained but at risk projects and needs to provide significant project rehabilitation support to not sustained projects. The ranking was made using the following definitions: 
Sustained project: The project obtains a $70 \%$ score (or more) in all sustainability dimensions, in aggregated form and in each core factor.

Sustained but at risk project: The project obtains a 70\% score (or more) in an aggregated form and in each core factor, but fails to obtain a 70\% score in any one of the sustainability dimensions.

Not sustained project: The project fails to obtain a 70\% score in an aggregated form or in any of the core factors.

\subsection{Design, setting, sample unit and tools}

A multi criteria participatory decision making approach was adopted during the implementation of the sustainability monitoring framework. The objective of this monitoring exercise was to decide the sustainability status of a range of completed projects supported by WaterAid Nepal (WAN). These projects have already been in operation for five years. The pilot study was intended to develop a standard sustainability monitoring framework for water supply and sanitation projects which could be utilized by WAN's partners and other sector agencies in Nepal and other developing countries. The objective of the project sampling was not only to generalize the sustainability outcome, but also to ensure the applicability of the sustainability framework to all types of existing projects. The study at the piloting phase included a representative selection of projects implemented in 13 districts of Nepal (4 terai, 9 hill and 3 urban projects). According to WaterAid Nepal's recent monitoring and evaluation (M\&E) report, the piloting phase has been successfully completed and the proven process is increasingly followed by its partners.

The field visit was conducted to gather information using different data collection strategies. The strategy included random water point and latrine inspection (sample surveys), focus group discussions, key informant interviews; transect walks, observations and photo capture. While soliciting information it was ensured that all the information was collected as accurately as possible. Fieldwork activity steps are presented in Figure 3. The rating system applied across quantitative and qualitative performance indicators.

\section{Field Activity Steps}

1. Arrival at project service area

2. Planning and arrangement for assessment

3. Complete village walk with community representatives

4. Key point observation, photo capture and sample survey

5. On the spot interview with household owners/students/passer by

6. Discussion and meeting with beneficiaries and their representatives

7. Completion of field judgment and assessment.

Figure 3. Field activity steps

\subsection{Data analysis and operation}

The study initially used the Weighted Table (WT) method to analyse the field data. The WT method is simple, cost effective and easily manageable at any organizational level, including local partner and field offices, by any computer literate person. WaterAid has further developed a spreadsheet-based programme package to manage data and analysis work. Further, the same information was analysed using AHP based software and a comparative evaluation of results from these two frameworks was conducted. As the comparative study between Weighted Table (WT) and AHP methods generated 
comparable composite sustainability values, the WT method could be utilized in future sustainability monitoring of projects even in the absence of AHP processing software. These two tools (or frameworks or methods) are perceived to be sustainability measuring yardsticks.

The MCA based sustainability monitoring framework is designed to be used at different levels - at the community level that operates the project systems, at the district level where the implementing agency provides technical backup supports, and at the funding agency level that provides financial supports for maintenance and rehabilitation. The AHP method is to be operated by highly skilled professionals; therefore it is limited at the WaterAid Nepal country office level for the moment. With the field experience and monitoring framework developed for the study, it is perceived that the MCA can be used at community level for the self-assessment of their water-sanitation-hygiene facilities by users themselves. It requires simplification of language, appropriate indicators and user-friendly analysis methodology. The community self-analysis tool could be developed in the form of paper or programmed electronic machines in the future. Project level information can also be gathered through telephone contacts between community representatives and the monitoring agency and fed into the sustainability database. At the bottom level, the framework is based on a weighted spreadsheet for participatory information collection and at the top level; the same information is to be used in an AHP framework to make decisions for resource allocation for sustainability enhancement.

\section{Key monitoring results}

An important outcome of the sustainability monitoring is that it helped rank the sustainability status of old projects by ecological regions, service types, settlement types etc. Overall sustainability ranking of the monitored projects shows that the majority of water and hygiene services fall under sustained but at risk category, whereas, majority sanitation services fall under the not sustained category. Table 3 below highlights on the overall sustainability ranking of the projects monitored so far by WaterAid Nepal.

Table 3. Sustainability results of projects

\begin{tabular}{|l|l|l|l|}
\hline \multirow{2}{*}{ Sector } & \multicolumn{3}{|l|}{ Number of services (projects) in percentage } \\
\cline { 2 - 4 } & Sustained (\%) & Sustained-risk (\%) & Not sustained (\%) \\
\hline Water services & 31 & 38 & 31 \\
\hline Sanitation services & 12 & 31 & 57 \\
\hline Hygiene services & 0 & 58 & 42 \\
\hline
\end{tabular}

Another major outcome of the study was a multiple criteria participatory framework for sustainability monitoring including identification of strong/weak areas which are contributing to maintaining/lowering the sustainability status. The study identified the criteria-wise contribution to the sustainability of projects, which is considered to be vital information for recommendations to increase the likelihood of sustainability in existing projects. Repeatedly occurring weak indicators across the studied projects also meant that there are areas for improvement in the future. Table 4 below highlights the key dimensions affecting sustainability in top down order, as one of the key results of the study.

Table 4. Key dimensions affecting sustainability

\begin{tabular}{|l|l|l|l|l|}
\hline \multirow{2}{*}{ Sector } & \multicolumn{4}{|l|}{ Poorly ranked criteria (in top down order) } \\
\cline { 2 - 5 } & $1^{\text {st }}$ & $2^{\text {nd }}$ & $3^{\text {rd }}$ & $4^{\text {th }}$ \\
\hline Water & Institutional & Financial & Social & Technical \\
\hline Sanitation & Institutional & Technical & Social & Financial \\
\hline Hygiene & Institutional & Sanitation facility & Water facility & Behavior \\
\hline
\end{tabular}




\section{Conclusion}

The pilot study developed a framework for sustainability monitoring of existing projects into the future. The framework gives the results of the sustainability status of projects based on their performance across various indicators included in the framework. Since the sustainability status of a project is dependent on the indicators used and weight and score distribution applied to the various indicators, the first and the foremost thing is that there should be consensus on indicators and weight distribution in the framework among all the concerned agencies that are using the framework in future. From the result of the study, it can be seen that there are considerable water, sanitation and hygiene facilities falling under the not sustained category among the selected projects. Adequate efforts should be put to address those causes (sub-factors) that have lower scores but higher weights (importance).

The application of AHP for sustainability monitoring of water and sanitation projects is instrumental to solve the complex sustainability ranking process, required for financial and policy decision making. This effort can be considered as one of the real life application of AHP in the development sector.

The utility of the framework can be improved by carrying out sensitivity analysis to see the effects of changes in weights of different sub-factors to the overall sustainability score. The system, although it was piloted in a considerable number of projects, needs further improvement in terms of technical, intellectual, contextual and methodological aspects in the future. This piece of work will help allow the beginning of a meaningful debate on the sustainability issue of existing projects in Nepal and other developing countries.

\section{REFERENCES}

Adams, W. M., (2006). The Future of Sustainability: Re-thinking Environment and Development in Twenty-first Century, Report of the IUCN Renowned Thinkers Meeting, 29-31 January 2006, The World Conservation Union (IUCN).

Bhattarai, S., \& Adhikari, B. K. (2008). Integrated Modeling Practiced in Nepal for Water Management, SaciWATERS. Third South Asian Water Research Conference, May 2008, Dhaka, Bangladesh.

DWSS \& WAN (2003). Unpublished Report on Survey of Old Water Supply and Sanitation Projects in Nepal, Department of Water Supply and Sanitation (DWSS) and WaterAid Nepal, Kathmandu, Nepal.

IUCN, UNEP \& WWF (1991). Caring for the Earth. A Strategy for Sustainable Living. Gland (Switzerland): IUCN/UNEP/WWF.

NEWAH (2005). A Report on NEWAH Looking Back Study (LBS), Nepal Water for Health (NEWAH), March 2005, Kathmandu, Nepal.

Panthi, K., \& Bhattarai, S. (2008). A Framework to Assess Sustainability of Community based Water Projects Using Multi Criteria Analysis, First International Conference on Construction in Developing Countries (ICCIDC-I), August 4-5, 2008, Karachi, Pakistan.

Sustainable Measures (2009). Internet: http://www.sustainablemeasures.com/, accessed on 31 May 2009.

Takashi, M. (2004), Design, Monitoring and Maintenance for Sustainable Civil Infrastructure, Alliance for Global Sustainability Research Report 2004-(2), Department of Civil Engineering, The University of Tokyo, Japan. 
WAN (2007). Long Term Sustainability Monitoring of Water Supply and Sanitation Projects, Project Report of WaterAid Nepal (WAN), conducted by Integrated Consultants Nepal Pvt. Ltd. (ICON), 2007, Kathmandu, Nepal.

WAN (2009). Long Term Sustainability of Water, Sanitation and Hygiene Projects, A Proceeding Paper, WaterAid Nepal, Kathmandu, Nepal. 